\title{
Management of pancreatogenic diabetes: challenges and solutions
}

This article was published in the following Dove Press journal:

Diabetes, Metabolic Syndrome and Obesity:Targets and Therapy

25 August 2016

Number of times this article has been viewed

\section{Jana Makuc}

Department of Internal Medicine, General Hospital Slovenj Gradec, Slovenj Gradec, Slovenia
Correspondence: Jana Makuc

General Hospital Slovenj Gradec,

Gosposvetska I, 2380 Slovenj Gradec,

Slovenia

Tel +3862 8823582

Fax +386 28823505

Email jana.makuc@sb-sg.si
Abstract: Pancreatogenic diabetes is an underdiagnosed form of secondary diabetes that is lacking official management guidelines. This paper reviews the recommended management strategies with additional data on the promising novel drugs.

Keywords: T3cDM, pancreatogenic diabetes, diabetes management, brittle diabetes, hypoglycemia

\section{Introduction}

Pancreatogenic diabetes is a form of secondary diabetes, classified by the American Diabetes Association (ADA) and the World Health Organization as type $3 \mathrm{c}$ diabetes mellitus (T3cDM) ${ }^{1,2}$ It refers to diabetes due to diseases of the exocrine pancreas: pancreatitis (acute, relapsing, or chronic pancreatitis of any etiology), pancreatectomy/trauma, neoplasia, cystic fibrosis, hemochromatosis, and fibrocalculous pancreatopathy. ${ }^{3}$ With the exception of cancer, damage to the pancreas must be extensive enough for diabetes to occur. ${ }^{1,2}$ Rather scarce data on T3cDM suggest that most cases result from chronic pancreatitis, as this condition was identified as the underlying disease in $78.5 \%$ of all patients with T3cDM. ${ }^{4}$

In Western populations, $\mathrm{T} 3 \mathrm{cDM}$ is estimated to occur in $5 \%-10 \%$ of all diabetic patients, mostly due to chronic pancreatitis. ${ }^{46}$ True prevalence of T3cDM is unknown data are scarce, mostly due to challenges with accurate diabetes classification in clinical practice. ${ }^{4,7-9}$ Many T3cDM patients are initially misclassified due to underrecognized contribution of pancreatic disease to the development of diabetes. In order to improve diagnosis, diagnostic criteria for T3cDM have been proposed by Ewald and Bretzel which include 1) the presence of pancreatic exocrine insufficiency, 2) evidence of pathological pancreatic imaging, and 3) the absence of type 1 diabetes mellitus (T1DM)associated autoantibodies. ${ }^{6}$ They may be further supported by additional minor criteria, such as an absent pancreatic polypeptide (PP) response to mixed-nutrient ingestion. ${ }^{6}$ These criteria may be more reliably applied at the presentation of diabetes due to a degree of overlap in established insulin deficiency (related to pancreatic atrophy and exocrine insufficiency). It is also worth noting that type 2 diabetes mellitus (T2DM) is common enough in the general population to accidentally coexist with exocrine pancreatic disease..$^{9,10}$

Despite the limited data, T3cDM patients appear to share a similar risk for the microand macro-vascular complications of diabetes as in T1DM and T2DM. ${ }^{11,12}$ Therefore, they should be equally monitored according to guidelines for patients with T1DM 
and T2DM. ${ }^{13,14}$ Unlike T1DM and T2DM that increase the risk of pancreatic cancer, $\mathrm{T} 3 \mathrm{cDM}$ is an effect and therefore a harbinger of pancreatic cancer in at least $30 \%$ of patients. ${ }^{15}$

\section{Pathophysiology}

Although classified as a unified group of secondary diabetes, the pathophysiological background of T3cDM differs. Damage to the pancreas disrupts the complex interplay of nutrient digestion, absorption, and utilization at different levels. Endocrine dysfunction represents deficiency of insulin, glucagon, PP, and incretin hormones. Typically, some degree of exocrine dysfunction with maldigestion and malabsorption of nutrients coexists. ${ }^{5,9,16}$

The pathogenesis of T3cDM is ultimately due to decreased insulin secretion; data on hepatic and peripheral tissue insulin sensitivity differ., ${ }^{917-19}$ Impaired counterregulation due to deficient glucagon secretion, blunted catecholamine response, and impaired activation of hepatic gluconeogenesis result in glycemic instability with hypoglycemic reactions. ${ }^{20}$

\section{Management}

Currently, there are no specific guidelines to manage T3cDM as a separate entity. Only two documents exist that can serve as recommendations for T3cDM diabetes management. ${ }^{13,14}$ For chronic pancreatitis, recommendations result from a consensus conference of gastroenterologists, endocrinologists, and surgeons with clinical and research expertise in the management of chronic pancreatitis and its complications. ${ }^{14}$ For cystic fibrosis patients, a position statement from the ADA is part of clinical care guidelines for cystic fibrosisrelated diabetes. $^{13}$

\section{Glycemic control}

The current ADA standard of diabetes care does not set specific glycemic targets for T3cDM. ${ }^{2}$ Therefore, as with T1DM and T2DM, the primary target is to achieve and maintain the $\mathrm{HbA} 1 \mathrm{c}<7 \%$ in order to minimize the risk of chronic complications. ${ }^{13,14}$ Keeping in mind the term "brittle diabetes", it is important to avoid hypoglycemia - blood glucose levels should be slightly above the normal to improve the quality of life. $5,8,20,21$

\section{Lifestyle modifications}

Attempts to reduce the toxic and modifiable contributors to chronic pancreatitis such as abstaining from alcohol and smoking cessation are highly recommended as both exacerbate progression of underlying pancreatic inflammation and fibrosis and contribute to pain. Abstaining from alcohol is also helpful for diabetes management, since alcohol acutely inhibits hepatic glucose production and can cause hypoglycemia, especially in the setting of insulin therapy. ${ }^{9}$ Due to its vital role in overall health, the guidelines for cystic fibrosisrelated $\mathrm{T} 3 \mathrm{cDM}$ also recommend moderate aerobic exercise for at least 150 minutes per week. ${ }^{13}$

\section{Nutrition}

In chronic pancreatitis-associated diabetes, preventing/ treating malnutrition, controlling symptoms of steatorrhea, and minimizing meal-induced hyperglycemia are the primary goals of medical nutritional therapy. ${ }^{14}$ Patients should be encouraged to eat meals that are rich in soluble fiber and low in fat. In case of pancreatic exocrine insufficiency (of any degree), concomitant oral enzyme replacement therapy should be prescribed. Oral pancreatic enzyme replacement is particularly important for fat digestion and nutrients absorption. It helps to control symptoms of steatorrhea, protect against fat-soluble vitamin deficiency, and is important for maintaining incretin hormone secretion and thus improving glucose tolerance. ${ }^{5,9,22-24}$ Vitamin D deficiency is frequently present in chronic pancreatitis, even in exocrine-sufficient patients. ${ }^{25}$ Osteoporosis frequency in these patients is $34 \%$, which is three times higher in comparison to controls. ${ }^{26}$

In cystic fibrosis-related T3cDM, similarly, good nutritional status and normal blood glucose levels are the primary goals. Patients are encouraged toward a well-balanced diet with no restriction in caloric intake, no fat, or carbohydrate restriction - all due to increased resting energy expenditure and malabsorption. Fat-soluble vitamins should be routinely supplemented. In contrast to other types of diabetes, there should be no salt and protein restriction in cystic fibrosisrelated T3cDM, even in the setting of concomitant arterial hypertension or microvascular complications. ${ }^{13}$

\section{Antihyperglycemic agents}

There are no current common guidelines for T3cDM treatment. Although T3cDM represents a unified group of secondary diabetes, the pathophysiological background differs. Therefore, different treatment options should be taken into account and tailored individually.

In chronic pancreatitis-associated diabetes with mild hyperglycemia $(\mathrm{HbAlc}<8 \%$ ), oral hypoglycemic agents may be appropriate. ${ }^{14}$ Metformin, an insulin sensitizer, should be considered in case of concomitant insulin resistance due to the theoretical rationale in reducing risk of pancreatic 
cancer., ${ }^{5,21,27-29}$ On the other hand, it is often badly tolerated due to gastrointestinal adverse effects and weight loss, which are undesired in chronic pancreatitis. ${ }^{9,14}$ Another group of insulin sensitizers, thiazolidinediones, are generally avoided due to their relation to fluid retention, congestive heart failure, and (particularly undesired) increased risk of fractures. ${ }^{14,30}$ Insulin secretagogues (sulfonylureas and glinides) increase the risk of malignancy and can cause hypoglycemia. ${ }^{5,27,31}$ If considered, short-acting agents are preferred, especially when meal ingestion is inconsistent. ${ }^{9}{ }^{14}$ Oral hypoglycemic agents are not recommended in cystic fibrosis-related T3cDM, as they are not as effective as insulin in improving nutritional and metabolic outcomes. ${ }^{13}$

Chronic pancreatitis patients with T3cDM not requiring insulin show a parallel to T2DM regarding the pathophysiology of the incretin defect and might benefit from incretin-based antidiabetic therapy. ${ }^{23}$ Incretin-based therapies (eg, GLP-1 analogs and DPP-IV inhibitors) enhance insulin secretion, but their use in these patients has been precluded due to association with cases of drug-induced pancreatitis. ${ }^{9,32,33}$ Also, GLP-1 analogs have been shown to reduce appetite and food intake leading to weight loss, which is not desired in these patients. ${ }^{34}$ Therefore, their use is not recommended until more data become available., ${ }^{9,14}$

There are also no current data available on use of potential sodium-glucose cotransporter 2 inhibitors in T3cDM patients. Although they seem efficient in T2DM management and do not cause hypoglycemia, their main side effect is weight loss, which is unwanted in T3cDM..$^{35,36}$

Insulin increases the risk of malignancy. ${ }^{5,27,31}$ But for most T3cDM patients, the principal endocrine defect is insulin deficiency, and therefore, insulin therapy is the preferred treatment. ${ }^{9}$ Insulin is the treatment of choice in cystic fibrosisrelated T3cDM. ${ }^{13}$ In this disease, insulin use is reported to improve outcomes in lung function, pulmonary exacerbation rates, nutritional status, blood glucose control, and decreased mortality. ${ }^{37-42}$ Insulin can also be used for other forms of T3cDM, especially for correcting hyperglycemia in chronic acutely ill or hospitalized patients and in severely malnourished patients (to whom the anabolic effects of insulin are particularly beneficial). ${ }^{9}{ }^{14}$ In advanced T3cDM, multidose basal-bolus insulin dosing regimens should follow guidelines for the treatment of T1DM, and include carbohydrate counting for flexible prandial coverage and consideration of continuous subcutaneous insulin infusion or "pump" delivery., ${ }^{9,13,14}$ However, in all insulin-based regimens, attention should be drawn to possible hypoglycemias. ${ }^{36}$ Deficient counterregulatory glucagon secretion from islet $\alpha$-cells, combined with blunted catecholamine response and impaired activation of hepatic gluconeogenesis, predisposes to hypoglycemia, which is often unpredictable in replacement doses of insulin. ${ }^{9,20,43}$

\section{Total pancreatectomy with islet autotransplantation}

It is a surgical method used in selected patients to treat severe complications (pain) of recurrent acute and chronic pancreatitis or in those with very high risk of pancreatic cancer while reducing the risk of severe diabetes mellitus. ${ }^{44}$ It does not serve as a prevention or treatment strategy of T3cDM per se, although it increases chances of good glycemic control. ${ }^{9}$ The selection criteria of patients are limitative, and therefore, the number of beneficiaries is very low. ${ }^{45}$

\section{Promising novel drugs}

PP has shown great promise as an antidiabetic drug for treatment of T3cDM secondary to chronic pancreatitis. ${ }^{46-50}$ It increases the expression of insulin receptors in the liver, thus enabling effective utilization of circulating insulin. ${ }^{49-52}$ It improves insulin sensitivity and decreases insulin requirements in T3cDM patients. ${ }^{49,52} \mathrm{~A}$ novel formulation of PP in stabilized phospholipid micelles has been shown to overcome the obstacle of PP's short biological half-life and demonstrate significant antidiabetic activity in a rodent model of pancreatogenic diabetes. ${ }^{53}$

\section{Conclusion}

There are no current common guidelines for T3cDM management. Management strategies balance on the edge between optimal glycemic control to minimize the risk of chronic complications and avoiding hypoglycemic reactions but at the same time address malnutrition and disturbing gastrointestinal symptoms of steatorrhea to improve the quality of life.

\section{Disclosure}

The author has received lecture fees from Sanofi Aventis, Novo Nordisk, AstraZeneca, and Boehringer Ingelheim. The author reports no other conflicts of interest in this work.

\section{References}

1. World Health Organization. Definition, diagnosis and classification of diabetes mellitus and its complications. Part 1: Diagnosis and classification of diabetes mellitus. Geneva: World Health Organization; 1999 [cited May 5, 2016]. Available from: http://apps.who.int/iris/bitstream/10665/66040/1/WHO_NCD_NCS_99.2.pdf. Accessed May 5, 2016. 
2. American Diabetes Association. Diagnosis and classification of diabetes mellitus. Diabetes Care. 2014;37(Suppl 1):S81-S90.

3. American Diabetes Association. Standards of medical care in diabetes 2016. Diabetes Care. 2016;39(Supp1 1):S1-S112.

4. Ewald N, Kaufmann C, Raspe A, Kloer HU, Bretzel RG, Hardt PD. Prevalence of diabetes mellitus secondary to pancreatic diseases (type 3c). Diabetes Metab Res Rev. 2012;28(4):338-342.

5. Cui Y, Andersen DK. Pancreatogenic diabetes: special considerations for management. Pancreatology. 2011;11(3):279-294.

6. Ewald N, Bretzel RG. Diabetes mellitus secondary to pancreatic diseases (Type 3c) - are we neglecting an important disease? Eur J Intern Med. 2013;24(3):203-206.

7. Hardt PD, Brendel MD, Kloer HU, Bretzel RG. Is pancreatic diabetes (type $3 \mathrm{c}$ diabetes) underdiagnosed and misdiagnosed? Diabetes Care. 2008;31(Suppl 2):S165-S169.

8. Andersen DK. The practical importance of recognizing pancreatogenic or type 3c diabetes. Diabetes Metab Res Rev. 2012;28(4):326-328.

9. Gudipaty L, Rickels MR. Pancreatogenic (type 3c) diabetes. Pancreapedia: Exocrine Pancreas Knowledge Base. 2015 [cited May 5, 2016]. Available from: http://www.pancreapedia.org/sites/www.pancreapedia. org/files/DOI\%20V3.\%20formatted\%20Type\%203c\%20DM\%20 chapter\%208-13-15.pdf. Accessed May 5, 2016.

10. Balzano G, Dugnani E, Pasquale V, et al. Clinical signature and pathogenetic factors of diabetes associated with pancreas disease (T3cDM): a prospective observational study in surgical patients. Acta Diabetol. 2014;51(5):801-811.

11. Couet C, Genton P, Pointel JP, et al. The prevalence of retinopathy is similar in diabetes mellitus secondary to chronic pancreatitis with or without pancreatectomy and in idiopathic diabetes mellitus. Diabetes Care. 1985;8(4):323-328.

12. Wang W, Guo Y, Liao ZA, et al. Occurrence of and risk factors for diabetes mellitus in Chinese patients with chronic pancreatitis. Pancreas. 2011;40(2):206-212.

13. Moran A, Brunzell C, Cohen RC, et al. Clinical care guidelines for cystic fibrosis-related diabetes: a position statement of the American Diabetes Association and a clinical practice guideline of the Cystic Fibrosis Foundation, endorsed by the Pediatric Endocrine Society. Diabetes Care. 2010;33(12):2697-2708.

14. Rickels MR, Bellin M, Toledo FGS, et al. Detection, evaluation and treatment of diabetes mellitus in chronic pancreatitis: recommendations from PancreasFest 2012. Pancreatology. 2013;13(4):336-342.

15. Magruder JT, Elahi D, Andersen DK. Diabetes and pancreatic cancer: chicken or egg? Pancreas. 2011;40(3):339-351.

16. Whitcomb D. Chronic pancreatitis, type $3 \mathrm{c}$ diabetes, and pancreatic cancer risk. JOP. 2014;15(5):2773.

17. Yasuda H, Harano Y, Ohgaku S, et al. Insulin sensitivity in pancreatitis, liver-diseases, steroid treatment and hyperthyroidism assessed by glucose, insulin and somatostatin infusion. Horm Metab Res. 1984;16(1):3-6.

18. Yki-Jarvinen H, Kiviluoto T, Taskinen MR. Insulin resistance is a prominent feature of patients with pancreatogenic diabetes. Metabolism. 1986;35(8):718-727.

19. Nathan JD, Zdankiewicz PD, Wang J, et al. Impaired hepatocyte glucose transport protein (GLUT2) internalization in chronic pancreatitis. Pancreas. 2001;22(2):172-178.

20. Tiengo A, Vigili de Kreutzenberg S, Del Prato S. Diabetes in pancreatitis, pancreatectomy and other pancreatic diseases. In: Ghigo E, Porta M, editors. Diabetes Secondary to Endocrine and Pancreatic Disorders. Front Diabetes. Vol. 22. Basel: Karger; 2014:119-143.

21. Cui Y, Andersen DK. Diabetes and pancreatic cancer. Endocr Relat Cancer. 2012;19(5):F9-F26.

22. Ebert R, Creutzfeldt W. Reversal of impaired GIP and insulin secretion in patients with pancreatogenic steatorrhea following enzyme substitution. Diabetologia. 1980;19(3):198-204.

23. Knop FK. Incretin hormones and beta cell function in chronic pancreatitis. Dan Med Bull. 2010;57(7):B4163.
24. Knop FK, Vilsboll T, Larsen S, et al. Increased postprandial responses of GLP-1 and GIP in patients with chronic pancreatitis and steatorrhea following pancreatic enzyme substitution. Am J Physiol Endocrinol Metab. 2007;292(1):E324-E330.

25. Sikkens ECM, Cahen DL, Koch AD, et al. The prevalence of fat-soluble vitamin deficiencies and a decreased bone mass in patients with chronic pancreatitis. Pancreatology. 2013;13(3):238-242.

26. Duggan SN, O'Sullivan M, Hamilton S, Feehan SM, Ridgway PF, Conlon KC. Patients with chronic pancreatitis are at increased risk for osteoporosis. Pancreas. 2012;41(7):1119-1124.

27. Li D, Yeung SC, Hassan MM, Konopleva M, Abbruzzese JL. Antidiabetic therapies affect risk of pancreatic cancer. Gastroenterology. 2009;137(2):482-488.

28. Libby G, Donnelly LA, Donnan PT, Alessi DR, Morris AD, Evans JM. New users of metformin are at low risk of incident cancer: a cohort study among people with type 2 diabetes. Diabetes Care. 2009;32(9):1620-1625.

29. Sadeghi N, Abbruzzese JL, Yeung SC, Hassan M, Li D. Metformin use is associated with better survival of diabetic patients with pancreatic cancer. Clin Cancer Res. 2012;18(10):2905-2912.

30. Kung J, Henry RR. Thiazolidinedione safety. Expert Opinion Drug Saf. 2012;11(4):565-579.

31. Bowker SL, Majumdar SR, Veugelers P, Johnson JA. Increased cancerrelated mortality for patients with type 2 diabetes who use sulfonylureas or insulin. Diabetes Care. 2006;29(2):254-258.

32. Elashoff M, Matveyenko AV, Gier B, Elashoff R, Butler PC. Pancreatitis, pancreatic, and thyroid cancer with glucagon-like peptide-1-based therapies. Gastroenterology. 2011;141(1):150-156.

33. Iyer SN, Tanenberg RJ, Mendez CE, Lee West R, Drake III AJ. Pancreatitis associated with incretin-based therapies. Diabetes Care. 2013;36(4):E49.

34. Larsen PJ. Mechanisms behind GLP-1 induced weight loss. Br J Diabetes Vasc Dis. 2008;8(Supp1 2):S34-S41.

35. Cefalu WT, Riddle MC. SGLT2 inhibitors: the latest "new kids on the block"! Diabetes Care. 2015;38(3):352-354.

36. Meier JJ, Giese A. Diabetes associated with pancreatic diseases. Curr Opin Gastroenterol. 2015;31(5):400-406.

37. Rolon MA, Benali K, Munck A, et al. Cystic fibrosis-related diabetes mellitus: clinical impact of prediabetes and effects of insulin therapy. Acta Paediatr. 2001;90(8):860-867.

38. Lanng S, Thorsteinsson B, Nerup J, Koch C. Diabetes mellitus in cystic fibrosis: effect of insulin therapy on lung function and infections. Acta Paediatr. 1994;83(8):849-853.

39. Mozzillo E, Franzese A, Valerio G, et al. One-year glargine treatment can improve the course of lung disease in children and adolescents with cystic fibrosis and early glucose derangements. Pediatr Diabetes. 2009;10(3):162-167.

40. Mohan K, Israel KL, Miller H, Grainger R, Ledson MJ, Walshaw MJ. Long-term effect of insulin treatment in cystic fibrosis related diabetes. Respiration. 2008;76(2):181-186.

41. Hardin DS, Rice J, Rice M, Rosenblatt R. Use of the insulin pump to treat cystic fibrosis-related diabetes. J Cyst Fibros. 2009;8(3):174-178.

42. Moran A, Dunitz J, Nathan B, Saeed A, Holme B, Thomas W. Cystic fibrosis-related diabetes: current trends in prevalence, incidence, and mortality. Diabetes Care. 2009;32(9):1626-1631.

43. Larsen S, Hilsted J, Tronier B, Worning H. Pancreatic hormone secretion in chronic pancreatitis without residual beta-cell function. Acta Endocrinol (Copenh). 1988;118(3):357-364.

44. Bellin MD, Freeman ML, Gelrud A, et al. Total pancreatectomy and islet autotransplantation in chronic pancreatitis: Recommendations from PancreasFest. Pancreatology. 2014;14(1):27-35.

45. Grigore C, Sarbu V, Simion S, Simion I, Poteca T, Nedelea S. Pancreatogenic diabetes patient selection for pancreatic islet transplantation. $J$ Med Life. 2010;3(1):84-89.

46. Sun YS, Brunicardi FC, Druck P, et al. Reversal of abnormal glucose metabolism in chronic pancreatitis by administration of pancreatic polypeptide. Am J Surg. 1986;151(1):130-140. 
47. Brunicardi FC, Chaiken RL, Ryan AS, et al. Pancreatic polypeptide administration improves abnormal glucose metabolism in patients with chronic pancreatitis. J Clin Endocrinol Metab. 1996;81(10):3566-3572.

48. Maeda H, Hanazaki K. Pancreatogenic diabetes after pancreatic resection. Pancreatology. 2011;11(2):268-276.

49. Rabiee A, Galiatsatos P, Salas-Carrillo R, Thompson MJ, Andersen DK, Elahi D. Pancreatic polypeptide administration enhances insulin sensitivity and reduces the insulin requirement of patients on insulin pump therapy. J Diabetes Sci Technol. 2011;5(6):1521-1528.
50. Hennig R, Kekis PB, Friess H, Adrian TE, Buchler MW. Pancreatic polypeptide in pancreatitis. Peptides. 2002;23(2):331-338.

51. Andersen DK. Mechanisms and emerging treatments of the metabolic complications of chronic pancreatitis. Pancreas. 2007;35(1):1-15.

52. Andersen DK, Andren-Sandberg Å, Duell EJ, et al. Pancreatitisdiabetes-pancreatic cancer: summary of an NIDDK-NCI workshop. Pancreas. 2013;42(8):1227-1237.

53. Banerjee A, Onyuksel H. A novel peptide nanomedicine for treatment of pancreatogenic diabetes. Nanomedicine. 2013;9(6):722-728.
Diabetes, Metabolic Syndrome and Obesity: Targets and Therapy is an international, peer-reviewed open-access journal committed to the rapid publication of the latest laboratory and clinical findings in the fields of diabetes, metabolic syndrome and obesity research. Original research, review, case reports, hypothesis formation, expert

\section{Dovepress}

opinion and commentaries are all considered for publication. The manuscript management system is completely online and includes a very quick and fair peer-review system, which is all easy to use. Visit http://www.dovepress.com/testimonials.php to read real quotes from published authors.

Submit your manuscript here: https://www.dovepress.com/diabetes-metabolic-syndrome-and-obesity-targets-and-therapy-journal 